\title{
Is There Publication Bias in the Reporting of Cancer Risk in Barrett's Esophagus?
}

\author{
NICHOLAS J. SHAHEEN, MELISSA A. CROSBY, EUGENE M. BOZYMSKI, and ROBERT S. SANDLER \\ Division of Digestive Diseases and Nutrition, Department of Medicine, and Center for Gastrointestinal Biology and Disease, University of \\ North Carolina at Chapel Hill, Chapel Hill, North Carolina
}

\section{See editorial on page 587.}

Background \& Aims: The published risk of adenocarcinoma in the setting of Barrett's esophagus (BE) varies. Publication bias, the selective reporting of studies featuring positive or extreme results, may result in overestimation of this cancer risk in the literature. The aim of this study was to assess those publications reporting a cancer risk in $\mathrm{BE}$ for evidence of publication bias. Methods: A MEDLINE search for all published estimates between 1966 and 1998 of cancer risk in BE was performed. All studies reporting a cancer risk expressible in cancers per patient-year of follow-up were retrieved. Bibliographies of these studies were surveyed for additional estimates. All publications that required an initial endoscopy with histologic confirmation of $\mathrm{BE}$ and any cancer were included. The relationship of reported cancer risk to size of the study was assessed. Multivariable regression controlling for differences in definition of $B E$, as well as other study characteristics, was performed. The data were also analyzed by means of a funnel diagram, an epidemiologic method to assess publication bias. Results: Five hundred fifty-four abstracts were reviewed. Twenty-seven publications met the stated criteria for inclusion. There was a strong correlation between cancer risk and the size of the study, with small studies reporting much higher risks of cancer than larger studies. This association persisted when differences in the definition of $B E$, retrospective vs. prospective nature of the study, surveillance interval, and the effect of cancer detected in the first year were considered. The funnel diagram analysis suggested publication bias. Conclusions: The cancer risk in BE may be overestimated in the literature due to publication bias.

B arrett's esophagus (BE) is a metaplastic change of the lining of the esophagus with replacement of the normal squamous mucosa by columnar intestinal-type mucosa. ${ }^{1}$ Patients with chronic gastroesophageal reflux disease (GERD) appear to be especially susceptible to BE. Because $\mathrm{BE}$ is known to be associated with an increased risk of adenocarcinoma of the esophagus, guidelines have been proposed for endoscopic screening of patients with long-standing reflux symptoms for the presence of BE. ${ }^{2}$ Those patients found to have $\mathrm{BE}$ on screening examinations would then be enrolled in endoscopic surveillance programs to monitor for dysplastic changes by periodic endoscopy. Despite the lack of clinical evidence showing a survival advantage in BE patients enrolled in endoscopic surveillance programs, this practice has become the standard of care.

The cost-effectiveness of endoscopic surveillance programs is unclear. BE is a common condition among those with frequent GERD, with a prevalence of approximately $10 \%$ of patients. ${ }^{3,4}$ Conversely, adenocarcinoma of the esophagus is a rare cause of cancer in the United States, with less than 10,000 cases nationwide in 1999. One of the primary determinants of the cost-effectiveness of surveillance strategies for $\mathrm{BE}$ is the underlying incidence of cancer among patients with BE. ${ }^{5}$ If the cancer incidence is high, then surveillance should be relatively cost-effective, with relatively few dollars spent per cancers detected. If the cancer incidence is low, then many endoscopies might be required to find one lesion, and cost-effectiveness will be poor. Unfortunately, estimates of cancer risk in $\mathrm{BE}$ are highly heterogeneous, ranging from $0 \%$ to almost 3\% per patient-year.

Publication bias is the selective reporting of studies featuring positive or extreme results. This bias has been suggested in a variety of clinical situations, ${ }^{6-9}$ and may result in misleading conclusions with respect to treatment effects or risk estimation. Additionally, meta-analysis of biased data may result in skewed conclusions. Finally, patients may be asked to enroll in studies to assess effectiveness of treatments already shown to be ineffective or even harmful. ${ }^{10}$

\footnotetext{
Abbreviations used in this paper: BE, Barrett's esophagus; GERD, gastroesophageal reflux disease.

( $\odot 2000$ by the American Gastroenterological Association 0016-5085/00/\$10.00 doi:10.1053/gast.2000.9302
} 
The purpose of this study was to systematically assess for publication bias in the reporting of the cancer risk in BE. If negative studies were less likely to be published, then the published literature might exaggerate the risk of adenocarcinoma, and overstate the potential value of screening and surveillance programs for $\mathrm{BE}$.

\section{Materials and Methods}

\section{Study Selection and Data Abstraction}

We assessed the English language literature for publications reporting a risk estimate for adenocarcinoma of the esophagus in the setting of BE. Computerized MEDLINE was used to assess publications from 1966 and 1998. The 2 main search strategies combined the keywords "Barrett's esophagus" with either "adenocarcinoma" or "esophageal neoplasms." All abstracts retrieved by this search strategy were reviewed. Those works reporting a cancer risk in the setting of $\mathrm{BE}$ were retrieved. The bibliographies of these articles were then scanned to identify additional articles for inclusion.

The authors used the following criteria for inclusion in the study: (1) any journal article or text reporting a cancer risk expressible in cancers per patient-year of follow-up; (2) endoscopy with biopsy at baseline for any patient included in the cohort; (3) histologic confirmation of BE of all patients in the cohort; and (4) histologic confirmation of any cancers during the follow-up period.

Estimates published solely in abstract form, as well as those with inadequate information to assess the previous criteria, were excluded. Published studies were abstracted by 2 investigators independently. Variables assessed included: year of publication, country of origin, cancer risk, retrospective vs. prospective design, endoscopic surveillance interval (categorized into 1 year, 2 years, $>2$ years, and no set interval), and number of cancers developing in the first year of follow-up. Because the definition of $\mathrm{BE}$ used by investigators varies, the pathologic definition of BE (categorized into specialized/intestinal, any columnar, and not specified), as well as length criteria of BE (categorized into columnar epithelium of any length, $>2 \mathrm{~cm},>3 \mathrm{~cm}$, other, and not specified) were also recorded. When noted, the percentage of patients undergoing a surgical antireflux procedure was also recorded. If serial publications reported cancer risk in the same cohort of patients, only the most recent report was included in the analysis.

\section{Data Analysis}

Cancer risks were calculated by dividing the number of cancers observed by the total number of patient-years of observation. Patients developing carcinoma were censored and no longer eligible to contribute patient-years of observation after their diagnosis. The agreement of abstracted data between investigators was assessed using the $\kappa$ statistic.

Simple linear regression was used to assess the relationship between the size of the study (reported in cumulative patientyears of follow-up), and the reported cancer risk. Multivariable

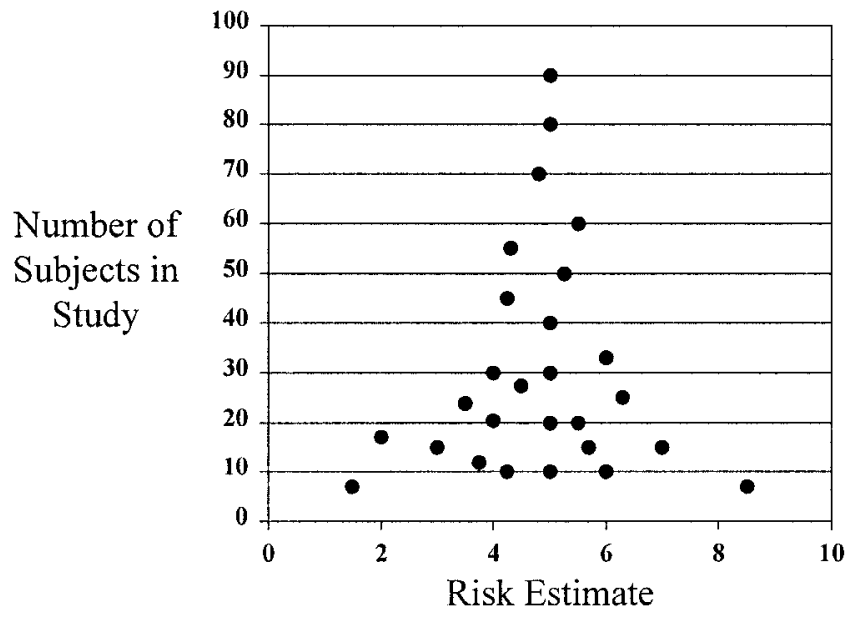

Figure 1. Sample funnel diagram showing no publication bias. "True" risk is 5. Estimated risks disperse evenly around "true" risk, with larger studies providing more accurate estimates.

regression was performed to assess this relationship, controlling for other potentially confounding variables including year of publication, definition of $\mathrm{BE}$, proportion of patients with surgical antireflux procedures, endoscopic surveillance interval, and retrospective vs. prospective study. No more than 3 predictor variables were assessed simultaneously. All regression analysis was performed using STATA 6.0 programs (College Station, TX).

Assessment of publication bias was performed using a modified funnel diagram. ${ }^{11,12}$ This is a graphic approach in which the size of the study (in this case the cumulative patient-years of follow-up of patients with BE) is plotted on the y-axis, and the measure of effect (here, the reported cancer risk) is plotted on the $\mathrm{x}$-axis. Because sampling error decreases as sample size increases, the cancer risk estimate should become more precise as the studies get larger. Therefore, when no publication bias exists, the smaller studies should be scattered evenly around the base of the funnel, and the larger studies should narrow to a point that approximates the true population risk (Figure 1). Conversely, when publication bias occurs, there may be selective publication of only those reports featuring high risks. In that case, there may be a "hole" in the base of the funnel, where smaller studies reporting more modest risks go unreported (Figure 2).

\section{Results}

Five hundred fifty-four abstracts were reviewed. Twenty publications met the stated criteria for inclusion. Of the remaining 534 abstracts, 530 dealt with other aspects of the association of carcinoma with BE, 2 reported combined incidences of dysplasia and cancer, and 2 did not have histologic data. Review of the bibliographies of the 20 retrieved articles yielded an additional 7 articles for inclusion. Two of these articles represented serial reports of the same cohort. Therefore, a total of 25 articles were included in the final analysis. ${ }^{13-37}$ Agree- 


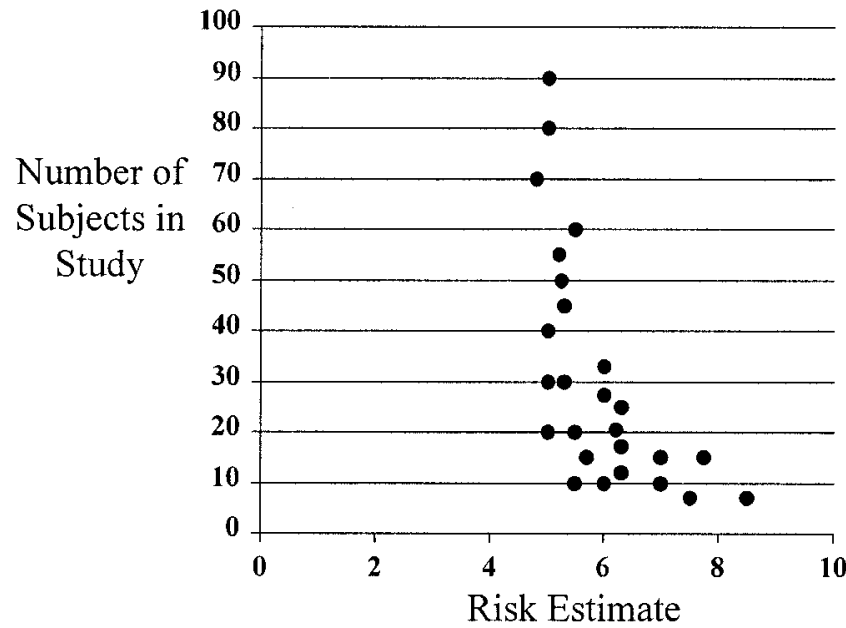

Figure 2. Sample funnel diagram suggesting publication bias. "True" risk is still 5. Estimated risks now collect at higher values for small studies, suggesting bias against publishing small studies with low risks.

ment for study inclusion between the reviewers was high $(\kappa=0.82)$.

Table 1 lists the studies analyzed, with the journal, year of publication, number of studies, cumulative patient-years of follow-up, incident cancers, age, and gender distribution. There was no correlation between year of publication and reported cancer risk. Additionally,

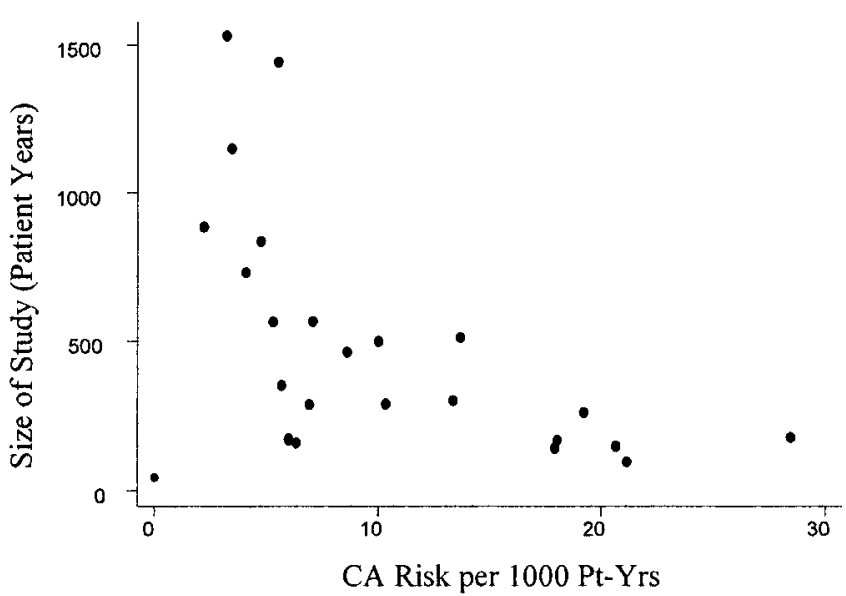

Figure 3. Reported cancer risk in BE vs. size of study.

cancer risk was not associated with the definition of $\mathrm{BE}$, length criteria for $\mathrm{BE}$, retrospective vs. prospective nature of the study, or proportion of patients undergoing surgical antireflux procedures. However, reported cancer risk was strongly associated in a negative curvilinear relationship with the size of the study $(P<0.01$; Figure 3$)$.

A funnel diagram was constructed by plotting the study size against the natural $\log$ of the reported cancer incidence (Figure 4). This diagram showed a paucity of small studies expressing low cancer risks.

Table 1. Publications Reporting the Risk of Esophageal Adenocarcinoma in Barrett's Esophagus

\begin{tabular}{|c|c|c|c|c|c|c|c|}
\hline Study & Journal/source & Year & No. of patients & $\begin{array}{l}\text { Patient-years } \\
\text { of follow-up }\end{array}$ & $\begin{array}{l}\text { No. of incident } \\
\text { cancers }\end{array}$ & $\begin{array}{l}\text { Average } \\
\text { age }(y r)\end{array}$ & Female (\%) \\
\hline Achkar and Carey ${ }^{13}$ & Am J Gastroenterol & 1988 & 62 & 166 & 1 & 56 & 26 \\
\hline Bartelsman et al. ${ }^{14}$ & Eur J Cancer Prev & 1992 & 50 & 260 & 5 & $\mathrm{n} / \mathrm{a}$ & $\mathrm{n} / \mathrm{a}$ \\
\hline Cameron et al.15 & N Engl J Med & 1985 & 104 & 882 & 2 & 60 & 31 \\
\hline \multicolumn{8}{|l|}{ Cooper and } \\
\hline Barbezat 16 & Q J Med & 1987 & 52 & 45 & 0 & 63 & 38 \\
\hline Csendes et al. ${ }^{17}$ & Surgery & 1998 & 151 & 1147 & 4 & 52 & 35 \\
\hline Drewitz et al. ${ }^{18}$ & Am J Gastroenterol & 1997 & 170 & 834 & 4 & 62 & 2 \\
\hline Ferraris et al. 19 & Eur J Gastroenterol Hepatol & 1997 & 187 & 562 & 3 & $\mathrm{n} / \mathrm{a}$ & $\mathrm{n} / \mathrm{a}$ \\
\hline Hameeteman et al. 20 & Gastroenterology & 1989 & 50 & 260 & 5 & 59 & 40 \\
\hline Iftikhar et al.21 & Gut & 1992 & 102 & 462 & 4 & 63 & 39 \\
\hline Katz et al. 22 & Am J Gastroenterol & 1998 & 102 & 563 & 3 & 63 & 17 \\
\hline McDonald et al. ${ }^{23}$ & J Thorac Cardiovasc Surg & 1996 & 112 & 728 & 3 & 68 & 31 \\
\hline Miros et al.24 & Gut & 1991 & 81 & 290 & 3 & 63 & 25 \\
\hline Moghissi et al.25 & Eur J Cardiothorac Surg & 1993 & 26 & 299 & 4 & 62 & 31 \\
\hline Ortiz et al. ${ }^{26}$ & $\mathrm{Br} J$ Surg & 1996 & 59 & 287 & 2 & 37 & 32 \\
\hline Ovaska et al. 27 & Dig Dis Sci & 1989 & 32 & 166 & 3 & 59 & 31 \\
\hline Reid et al. 28 & Gastroenterology & 1992 & 62 & 176 & 5 & 62 & 18 \\
\hline Robertson et al. ${ }^{29}$ & Br J Surg & 1988 & 56 & 168 & 3 & 62 & 45 \\
\hline Savary et al. ${ }^{30}$ & Text & 1984 & 402 & 1528 & 5 & $\mathrm{n} / \mathrm{a}$ & $\mathrm{n} / \mathrm{a}$ \\
\hline Skinner31 & Text & 1989 & 45 & 145 & 3 & $\mathrm{n} / \mathrm{a}$ & $\mathrm{n} / \mathrm{a}$ \\
\hline Spechler et al. 32 & Gastroenterology & 1984 & 105 & 350 & 2 & $\mathrm{n} / \mathrm{a}$ & $\mathrm{n} / \mathrm{a}$ \\
\hline Streitz et al. ${ }^{33}$ & Am J Gastroenterol & 1998 & 149 & 510 & 7 & $\mathrm{n} / \mathrm{a}$ & $\mathrm{n} / \mathrm{a}$ \\
\hline van der Burgh et al.34 & Gut & 1996 & 155 & 1440 & 8 & 62 & 42 \\
\hline Watson et al. 35 & Eur J Gastroenterol Hepatol & 1991 & 45 & 158 & 1 & 63 & 51 \\
\hline Weston et al. ${ }^{36}$ & Am J Gastroenterol & 1997 & 55 & 94 & 2 & 63 & 24 \\
\hline Williamson et al. 37 & Arch Intern Med & 1991 & 176 & 497 & 5 & 56 & 35 \\
\hline
\end{tabular}

$\mathrm{n} / \mathrm{a}$, not available. 


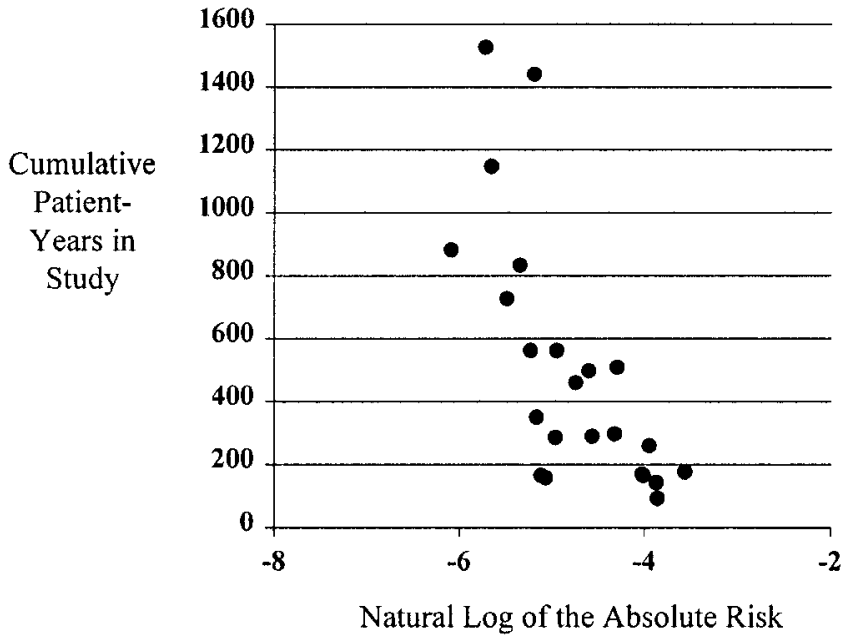

Figure 4. Modified funnel diagram of cancer risk in BE.

\section{Discussion}

This study shows an inverse relationship between study size and reported cancer risk in the setting of BE. One possible explanation for this observation is that publication bias has occurred. Investigators with small studies demonstrating modest cancer risks may be reluctant to submit these findings for publication because of fear of rejection. Alternatively, editors may feel that small negative studies are not newsworthy, whereas small studies showing high risks may be more appealing.

There are other potential reasons for this observation. Perhaps the studies vary in some systematic way, such that the smaller studies encompass patients at higher risk for carcinoma than the large studies. For instance, if the smaller studies included only those patients with intestinal-type epithelium, whereas the larger studies included patients with any columnar epithelium, the smaller studies might be expected to show a higher risk of neoplasia. However, in multivariable regression, definition of $\mathrm{BE}$, length of $\mathrm{BE}$, proportion of surgically altered patients, country of origin, and retrospective vs. prospective design of the study were not found to be significantly associated with the reported cancer risk. Furthermore, although the risk of adenocarcinoma of the esophagus appears to be rising, ${ }^{38}$ controlling for the year of publication did not alter the relationship between study size and cancer risk. Therefore, it seems unlikely that some other methodologic or demographic feature of the studies accounts for the observed association between study size and cancer risk. Similarly, temporal changes in the epidemiology of adenocarcinoma of the esophagus do not explain these findings.

Detection bias might also explain the association of cancer risk and study size. This bias might be shown in multiple ways. First, if smaller studies also had more intense endoscopic surveillance protocols, more cancer cases might be detected. However, there was no significant relationship between endoscopic surveillance interval and either study size or cancer risk. Second, patients in the smaller studies had a shorter mean follow-up period. If the initial endoscopy missed an already existing cancer, the number of incident cancers in the follow-up period might be artificially inflated by the inclusion of these missed prevalent cancers. Because the smaller studies have fewer follow-up years per patient, there would be less dilution of the effect of missed prevalent cancers. To assess the importance of missed prevalent cancers, we reanalyzed the data after excluding all carcinomas diagnosed in the first year of follow-up in those studies providing longitudinal data $(\mathrm{n}=18)$. Excluding these cases did not affect the strong inverse relationship between study size and reported cancer risk.

The use of a funnel diagram to assess for publication bias implies several assumptions. First, we must assume that large studies reporting modest cancer risks are less likely to be suppressed by either authors or editors than similar small studies. Although this makes intuitive sense, this assumption cannot be evaluated. ${ }^{39}$ Additionally, this technique is primarily graphic, as opposed to quantitative, and funnel plots may be interpreted differently by different investigators. Previous attempts have been made to assess funnel plot asymmetry numerically; however, the validity of these approaches has been questioned. ${ }^{40} \mathrm{Next}$, data retrieval from the literature must be thorough. Although rigorous attempts were made to locate all studies conforming to our criteria, it is possible, and perhaps likely, that some studies escaped our notice. ${ }^{41}$ Finally, funnel plot techniques imply no assessment of study quality beyond the criteria defined by the researcher for study inclusion. Although large studies are often of higher methodologic quality than smaller studies, this is not universally true. In the present study, studies appearing solely in abstract form were not eligible for inclusion. Although such data are important, the lack of information in abstracts with respect to demographics, definition of $\mathrm{BE}$, surveillance protocols, surgically altered patients, and other potential confounders made the previously mentioned analysis untenable using these data. There is also the theoretical concern that data appearing solely as abstracts may be of poorer quality than those published in journals.

The presence of possible publication bias in the assessment of the cancer risk in BE has several implications. Although widely practiced, periodic endoscopic surveillance of patients with $\mathrm{BE}$ has not been shown to decrease cancer incidence or increase life expectancy. Previous 
investigators modeling the utility of endoscopic surveillance of patients with BE have shown that the underlying incidence of adenocarcinoma of the esophagus is a primary determinant of the cost-effectiveness of endoscopic surveillance. ${ }^{5,33}$ If this incidence is lower than previously thought, we might be overemphasizing the benefit of costly screening programs. Additionally, several investigators have combined data from studies reporting cancer risk in BE in an attempt to generate a summary statistic of cancer risk. ${ }^{18,33}$ Such mixing of heterogeneous estimates from large and small studies in meta-analysis may result in inflated estimates of cancer risk. Although the results of this study do not allow for the ascertainment of the cancer risk in $\mathrm{BE}$, the point of the funnel appears to be at an incidence of approximately $0.5 \%$ per patientyear.

In conclusion, in studies reporting the incidence of adenocarcinoma of the esophagus in the setting of $\mathrm{BE}$, there is a strong inverse relationship between the size of the study and the reported cancer risk. Potential confounders, such as date of publication, definition of Barrett's used, proportion of patients with surgical antireflux procedures, and inclusion of prevalent cases, do not appear to explain this association. Publication bias, such that smaller studies are published only if they feature high cancer risks, is a possible explanation for the observed association. Policy makers wishing to create patient care guidelines based on the literature should be aware of this potential bias.

\section{References}

1. Bozymski EM, Herlihy KJ, Orlando RC. Barrett's esophagus. Ann Intern Med 1982;97:103-107.

2. Sampliner RE. Practice guidelines on the diagnosis, surveillance, and therapy of Barrett's esophagus. The Practice Parameters Committee of the American College of Gastroenterology. Am J Gastroenterol 1998;93:1028-1032.

3. Winters CJ, Spurling TJ, Chobanian SJ, Curtis DJ, Esposito RL, Hacker JF, Johnson DA, Cruess DF, Cotelingam JD, Gurney MS. Barrett's esophagus. A prevalent, occult complication of gastroesophageal reflux disease. Gastroenterology 1987;92:118124.

4. Mann NS, Tsai MF, Nair PK. Barrett's esophagus in patients with symptomatic reflux esophagitis. Am J Gastroenterol 1989;84: 1494-1496.

5. Provenzale D, Schmitt C, Wong JB. Barrett's esophagus: a new look at surveillance based on emerging estimates of cancer risk. Am J Gastroenterol 1999;94:2043-2053.

6. Callaham ML, Wears RL, Weber EJ, Barton C, Young G. Positiveoutcome bias and other limitations in the outcome of research abstracts submitted to a scientific meeting. JAMA 1998;280: 254-257.

7. Stern JM, Simes RJ. Publication bias: evidence of delayed publication in a cohort study of clinical research projects. BMJ 1997; 315:640-645.

8. Dickersin K. How important is publication bias? A synthesis of available data. AIDS Educ Prev 1997;9:15-21.

9. Allison DB, Faith MS, Gorman BS. Publication bias in obesity treatment trials? Int J Obes Relat Metab Disord 1996;20:931937.

10. Horton R. Medical editors trial amnesty. Lancet 1997;350:756.

11. Light RJ, Pillemer DB. Summing up. The science of reviewing research. Cambridge, MA: Harvard University Press, 1984.

12. Egger M, Davey SG, Schneider M, Minder C. Bias in meta-analysis detected by a simple, graphical test. BMJ 1997;315:629634.

13. Achkar E, Carey W. The cost of surveillance for adenocarcinoma complicating Barrett's esophagus. Am J Gastroenterol 1988;83: 291-294.

14. Bartelsman JF, Hameeteman W, Tytgat GN. Barrett's oesophagus. Eur J Cancer Prev 1992;1:323-325.

15. Cameron AJ, Ott BJ, Payne WS. The incidence of adenocarcinoma in columnar-lined (Barrett's) esophagus. N Engl J Med 1985;313: 857-859.

16. Cooper BT, Barbezat GO. Barrett's oesophagus: a clinical study of 52 patients. Q J Med 1987;62:97-108.

17. Csendes A, Braghetto I, Burdiles P, Puente G, Korn O, Diaz JC, Maluenda F. Long-term results of classic anti-reflux surgery in 152 patients with Barrett's esophagus: clinical, radiologic, endoscopic, manometric, and acid reflux test analysis before and late after operation. Surgery 1998;126:645-657.

18. Drewitz DJ, Sampliner RE, Garewal HS. The incidence of adenocarcinoma in Barrett's esophagus: a prospective study of 170 patients followed 4.8 years [see comments]. Am J Gastroenterol 1997;92:212-215.

19. Ferraris R, Bonelli L, Conio M, Fracchia M, Lapertosa G, Aste H. Incidence of Barrett's adenocarcinoma in an Italian population: an endoscopic surveillance programme. Gruppo Operativo per lo Studio delle Precancerosi Esofagee (GOSPE). Eur J Gastroenterol Hepatol 1997;9:881-885.

20. Hameeteman W, Tytgat GN, Houthoff HJ, van den Tweel JG. Barrett's esophagus: development of dysplasia and adenocarcinoma. Gastroenterology 1989;96:1249-1256.

21. Iftikhar SY, James PD, Steele RJ, Hardcastle JD, Atkinson M. Length of Barrett's oesophagus: an important factor in the development of dysplasia and adenocarcinoma. Gut 1992;33: 1155-1158.

22. Katz D, Rothstein R, Schned A, Dunn J, Seaver K, Antonioli D. The development of dysplasia and adenocarcinoma during endoscopic surveillance of Barrett's esophagus. Am J Gastroenterol 1998;93:536-541.

23. McDonald ML, Trastek VF, Allen MS, Deschamps C, Pairolero PC. Barretts's esophagus: does an anti-reflux procedure reduce the need for endoscopic surveillance? J Thorac Cardiovasc Surg 1996;111:1135-1138.

24. Miros M, Kerlin P, Walker N. Only patients with dysplasia progress to adenocarcinoma in Barrett's oesophagus. Gut 1991; 32:1441-1446.

25. Moghissi K, Sharpe DA, Pender D. Adenocarcinoma and Barrett's oesophagus. A clinico-pathological study. Eur J Cardiothorac Surg 1993;7:126-131.

26. Ortiz A, Martinez dHL, Parrilla P, Morales G, Molina J, Bermejo, J, Liron R, Aguilar J. Conservative treatment versus anti-reflux surgery in Barrett's oesophagus: long-term results of a prospective study. Br J Surg 1996;83:274-278.

27. Ovaska J, Miettinen M, Kivilaakso E. Adenocarcinoma arising in Barrett's esophagus. Dig Dis Sci 1989;34:1336-1339.

28. Reid BJ, Blount PL, Rubin CE, Levine DS, Haggitt RC, Rabinovitch PS. Flow-cytometric and histological progression to malignancy in Barrett's esophagus: prospective endoscopic surveillance of a cohort. Gastroenterology 1992;102:1212-1219.

29. Robertson CS, Mayberry JF, Nicholson DA, James PD, Atkinson M. Value of endoscopic surveillance in the detection of neoplastic change in Barrett's oesophagus. Br J Surg 1988;75:760763. 
30. Savary M, Ollyo JB, Monnier P. Frequency and importance of endobrachyesophagus in reflux disease. In: Siewert JR, Holscher $\mathrm{AH}$, eds. Diseases of the esophagus. New York: Springer-Verlag, 1984:529-536.

31. Skinner DB. The incidence of cancer in Barrett's esophagus varies according to the series. In: Giuli R, McCallum RW, eds. Benign lesions of the esophagus and cancer. New York: SpringerVerlag, 1989:764-765.

32. Spechler SJ, Robbins AH, Rubins HB, Vincent ME, Heeren $T$, Doos WG, Colton T, Schimmel EM. Adenocarcinoma and Barrett's esophagus. An overrated risk? Gastroenterology 1984;87: 927-933.

33. Streitz JMJ, Ellis FHJ, Tilden RL, Erickson RV. Endoscopic surveillance of Barrett's esophagus: a cost-effectiveness comparison with mammographic surveillance for breast cancer. Am J Gastroenterol 1998;93:911-915.

34. van der Burgh A, Dees J, Hop WC, Van Blankenstein M. Oesophageal cancer is an uncommon cause of death in patients with Barrett's oesophagus. Gut 1996;39:5-8.

35. Watson RG, Porter KG, Sloan JM. Incidence of adenocarcinoma in Barrett's esophagus and an evaluation of endoscopic surveillence. Eur J Gastroenterol Hepatol 1991;3:159-162.

36. Weston AP, Krmpotich PT, Cherian R, Dixon A, Topalosvki M. Prospective long-term endoscopic and histological follow-up of short segment Barrett's esophagus: comparison with traditional long segment Barrett's esophagus. Am J Gastroenterol 1997;92: 407-413.

37. Williamson WA, Ellis FHJ, Gibb SP, Shahian DM, Aretz HT, Heatley GJ, Watkins E. Barrett's esophagus. Prevalence and incidence of adenocarcinoma. Arch Intern Med 1991;151:2212-2216.

38. Daly JM, Karnell LH, Menck HR. National Cancer Data Base report on esophageal carcinoma. Cancer 1996;78:1820-1828.

39. Vandenbroucke JP. Bias in meta-analysis detected by a simple, graphical test. Experts' views are still needed [letter; comment]. BMJ 1998;316:469-470.

40. Begg CB, Mazumdar M. Operating characteristics of a rank correlation test for publication bias. Biometrics 1994;50:10881101.

41. Knipschild P. Systematic reviews. Some examples. BMJ 1994; 309:719-721.

Received January 7, 2000. Accepted March 30, 2000.

Address requests for reprints to: Nicholas J. Shaheen, M.D., M.P.H., Department of Medicine, CB\#7080, University of North Carolina, Chapel Hill, North Carolina 27599-7080. e-mail: nshaheen@ med.unc.edu; fax: (919) 966-6842. 